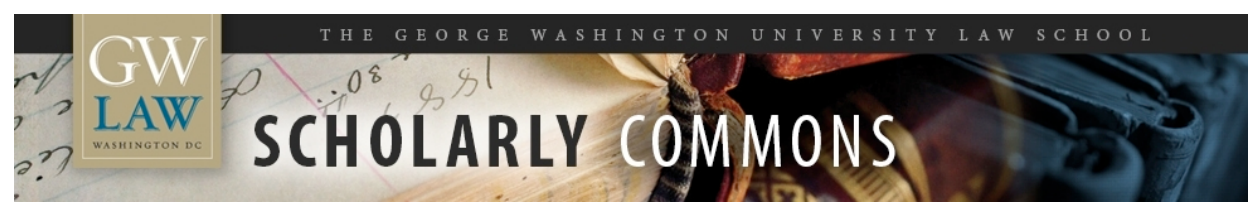

\title{
Takeaways from the Conference on the Future of White House Regulatory Oversight and Cost-Benefit Analysis
}

Richard J. Pierce Jr

George Washington University Law School, rpierce@law.gwu.edu

Follow this and additional works at: https://scholarship.law.gwu.edu/faculty_publications

Part of the Law Commons

\section{Recommended Citation}

Pierce, Richard J., Takeaways from the Conference on the Future of White House Regulatory Oversight and Cost-Benefit Analysis (2019). GWU Law School Public Law Research Paper No. 2019-60; GWU Legal Studies Research Paper No. 2019-60. Available at SSRN: https://ssrn.com/abstract=3459052

This Article is brought to you for free and open access by the Faculty Scholarship at Scholarly Commons. It has been accepted for inclusion in GW Law Faculty Publications \& Other Works by an authorized administrator of Scholarly Commons. For more information, please contact spagel@law.gwu.edu. 


\title{
Takeaways from the Conference on the Future of White House Regulatory Oversight and Cost-Benefit Analysis
}

\author{
Richard J. Pierce, Jr.
}

\begin{abstract}
This is Professor Pierce's summary of a conference on the future of White House regulatory oversight and cost-benefit analysis (cba), along with an explanation of his views on the controversial issues that were discussed.

The participants agreed that OIRA should encourage ex post evaluations of rules, extend oversight to independent agencies, and continue its efforts to maximize the transparency of the review process. They also agreed that Congress should provide OIRA adequate funding and staffing.

Professor Pierce explained why he shares the concern of some of the other participants that the major changes that the Trump Administration is making in the methods used to apply cba, and the resulting major changes in the estimates of the costs and benefits of rules, will undermine the bipartisan consensus in support of bca that has survived through five prior administrations.

Professor Pierce also explained his views with respect to changes in the oversight process that were proposed by some participants and opposed by others. He explained why he opposes codifying cba and increasing Congress's role in the process of applying cba. He also explained why he believes that any economically rational regulatory budget must have a regulatory cost ceiling that is many times the current cost of regulation.
\end{abstract}

On September 13, 2019, the Boyden Gray Center for the Study of the Administrative State hosted a conference on the future of White House regulatory oversight and cost-benefit analysis (CBA). This essay is my attempt to summarize the main issues that were discussed at the conference and my views on each of those issues. I divide the issues into three categories: reasons for celebration, reasons for concern, and serious questions that need to be addressed.

\section{Reasons for Celebration}

The conference highlighted three reasons why proponents of White House oversight and cba should celebrate. First, as Jim Tozzi and Susan Dudley described in detail, White House oversight and application of cba has proven to be extraordinarily durable. It has thrived, developed and matured through six 
presidential administrations of both parties and a wide range of ideological perspectives despite the persistent attacks of many critics on its legitimacy and propriety.

Second, as Paul Noe and John Graham explained in detail, the courts have gradually changed their attitude toward cba from initial skepticism to enthusiastic embrace. The opinions of all nine Justices in Michigan v. $E P A^{1}$ leave no doubt that the courts approve of the use of cba in regulatory decision making and will require agencies to use it except in the rare case in which Congress has explicitly forbidden consideration of costs.

Third, the conference illustrated the reality that these remarkable successes are attributable to many extraordinary people, including talented regulatory economists, dedicated civil servants, scholars in several fields and the gifted managers that six presidents of both parties appointed to oversee the operations of the Office of Information and Regulatory Affairs (OIRA).

Jim Tozzi deserves special recognition because of his role as one of the founders of the field of regulatory analysis and his continuing roles in developing the field over the past five decades. Susan Dudley and Sally Katzen deserve special recognition because of their continuing efforts to propose and support bipartisan improvements to the process of presidential oversight of the regulatory process.

\section{Reason for Concern}

The conference identified only one reason for concern about the future of White House regulatory oversight and cba, but it is a matter of grave concern. Stuart Shapiro described the many actions of the Trump Administration that are creating an environment that threatens to destroy the broad bipartisan support for regulatory oversight and cba that persisted over the prior five administrations. Those actions fall in three categories.

\footnotetext{
${ }^{1} 135$ S. Ct. 2699 (2015).
} 
First, President Trump's Executive Orders consistently ignore the benefits of regulations and require agencies to take actions that are based solely on his stated goal of repealing all rules that were issued after 1960 without giving any consideration to the hundreds of billions of dollars in benefits those rules produced.

Second, while OIRA has repeatedly restated its intention to continue to apply cba to all proposed major regulatory actions during the Trump Administration, many observers give its efforts to do so low marks. As Shapiro documents in detail, "no previous administration has seen its analyses so regularly and quickly criticized as the Trump Administration."

Third, other agencies in the Trump Administration, most notably EPA, have proposed changes in cba that would have the effect of producing estimates that rules would produce billions of dollars in net costs even though the agency previously estimated that the same rules would produce billions of dollars in net benefits.

EPA and OIRA have joined hands to make many changes in the methods they use to estimate the costs and benefits of rules over the last thirty years. Efforts of that type are essential to reflect our constantly evolving understanding of the difficulty of the task of estimating costs and benefits and the best ways to accomplish that task. Each of the major changes that EPA has proposed in the Trump Administration should be the subject of study and debate, but the combined effect of the many proposed changes leaves no doubt that the Trump Administration is trying to make every conceivable change that could help it accomplish President Trump's stated goal of repealing every rule that was issued after 1960 without considering seriously the hundreds of billions of dollars in benefits that the rules have produced for society.

The Trump Administration's proposals to make dramatic changes in traditional methods of implementing cba have been most extreme in the context of efforts to mitigate climate change. The Obama 
Administration estimated the social cost of emissions of carbon dioxide-the most important cause of climate change--as $\$ 25$ per ton. Courts have upheld many rules on the basis of that estimate. ${ }^{2}$ The changes proposed by the Trump Administration would reduce the estimated cost of carbon dioxide emissions by over ninety per cent, thereby reducing the estimated benefits of mitigating climate change by over ninety per cent. It will be difficult for the Administration to defend the massive reductions in the estimated cost of emissions of emissions of carbon dioxide it is proposing in light of the eye-popping new estimates of the cost of climate change that have been announced by widely-respected organizations. ${ }^{3}$ Those estimates strongly suggest that the Obama Administration greatly underestimated the cost of emissions of carbon dioxide.

If the Trump Administration is successful in its attempts to change the methods of implementing cba to the extent that agencies regularly "correct" their prior cbas by estimating that actions that they previously estimated would produce billions of dollars in net benefits actually will produce billions of dollars in net costs, it will be responsible for complete abandonment of any future attempt to use cba as a tool in making regulatory decisions. No tool is useful if it can yield results that diverge as dramatically as the changes in cba proposed by the Trump Administration suggest.

As a long-time proponent of the use of $\mathrm{cba}$ as a tool in making regulatory decisions, I would be disappointed to see it discredited and abandoned. I hope that those who agree with my belief that cba is a valuable tool and my fear that the Trump Administration might end the decades of bipartisan support for cba will join me in my efforts to keep this from happening.

\section{Questions that Must Be Addressed}

\footnotetext{
2 See Danielle A. Farber, Regulatory Review in Anti-Regulatory Times, 94 Chi. K. L. Rev. 383 (2019).

${ }^{3}$ Thus, for instance, the National Bureau of Economic Research has estimated that climate change will cost the U.S. $10.5 \%$ of its GDP by 2100. NBER Working Paper 26167 (Aug. 2019).
} 
The conference identified several reasons for optimism about the future of White House review and cba and one reason for concern about that future. Most of the attention was devoted to discussion of potential changes in regulatory oversight and cba that were proposed by some participants.

Four of the proposed changes are hardy perennials that were supported by most if not all of the participants. (1) Agencies should increase their use of ex post evaluation of rules to determine whether the initial estimates of costs and benefits were reasonably accurate and to make any changes in rules that are suggested by the ex post evaluations. (2) OIRA's review of the costs and benefits of major rules should be extended to the "independent" agencies. (3) OIRA should continue its efforts to improve the transparency of the review process. (4) Congress and the President should insure that OIRA has enough funding and staffing to accomplish its mission effectively.

Each of those proposals has been the subject of a great deal of scholarly writing and none provoked significant debate at the conference. The discussion of each focused primarily on identifying ways of overcoming the political obstacles and resource constraints that limit the efficacy of attempts to implement each of those proposals.

Four proposals triggered lively debates: (1) proposals to supplement cba with a cost-only regulatory budget; (2) proposals to codify regulatory review and cba by issuing a legislative rule or enacting a statute that legitimates regulatory review and requires agencies to use cba; (3) proposals to give Congress a greater role in the regulatory review process in various ways; and, (4) proposals to change the review process in ways that would improve the ability to separate and reconcile the often competing goals of furthering economic efficiency and ensuring political accountability for regulatory actions.

Regulatory Budgets: Several participants urged adoption of a cost-only regulatory budget as a complement to cba. Jim Tozzi argued that cba alone was inadequate to protect the country from the potential for excessive regulation that produces net detriments to society. He argued in support of a cost- 
only regulatory budget as a necessary complement to cba because of the risk that we might invest scarce capital in regulation when it could yield a better return if we invested it in other ways. In Tozzi's words: "Therefore, the nation is confronted with a potential shortage - at an exceedingly high opportunity costof capital to finance the totality of regulations whose benefits exceed their costs."

Tozzi recognized that any economically rational regulatory budget would have to include an economically rational ceiling on the total cost of regulation and that the economically rational ceiling would not necessarily be the zero incremental cost ceiling that President Trump imposed in Order 13,771. I suggested that we could use OIRA's annual cba report as the basis to decide whether to adopt a regulatory budget and to establish an economically rational ceiling on regulatory costs if we decide to create a regulatory budget.

OIRA reviews and approves the cbas that all executive agencies are required to prepare with respect to every major rule. OIRA then makes an annual report to Congress in which it reports the total costs and benefits of all of the rules that OIRA reviewed and that agencies issued during the prior decade. OIRA reports total benefits that are approximately seven times as great as total costs. ${ }^{4}$

The massive disproportion between the costs and benefits of regulation provide solid evidence that investments in regulation earn similarly massive returns. According to OIRA, the average return on investment in a major rule is 600 per cent. It is hard to imagine any other investment that could be made either by government or by a private firm that would have a return that high.

Tozzi also makes the point that OIRA's cba estimates reflect only the cost of major rules. Minor rules that are not the subject of cbas also impose regulatory costs that should be included in the total cost of

\footnotetext{
${ }^{4}$ OIRA, Report to Congress on the Benefits and Costs of Federal Regulations (2015).
} 
regulation. That is true, but minor rules also create social benefits. We have no way of knowing whether the cost-benefit ratio of minor rules is higher or lower than the cost-benefit ratio of major rules.

Minor rules could easily have cost-benefit ratios that are identical to those of major rules. If that is the case, our failure to include the costs and benefits of minor rules has no effect on the conclusion that investments in regulation provide returns far in excess of the alternative investments we could make. Even if we assume-implausibly-that minor rules impose aggregate costs that equal the aggregate costs of major rules and that they provide no benefits, the return on investment in regulation would be 300 per cent.

The OIRA reports suggest that the economically rational ceiling on aggregate regulatory costs is several times the total cost of regulation today. They also provide an attractive alternative to establishing a regulatory budget subject to a ceiling on total regulatory costs. We can determine whether the return on investment in government regulation is so low that we might be better off investing in alternative ways of improving social welfare simply by monitoring the annual OIRA reports of the costs and benefits of rules. If and when the ratio between benefits and costs declines to 110 per cent, we should be concerned that we might be overinvesting in regulation because there might be alternative investments that would have a higher rate of return than the ten per cent implied by such a ratio.

Codification of regulatory review and cba. Several participants proposed codification of the use of cba in the process of regulatory review either through issuance of a rule by OIRA or through enactment of a statute by Congress. The proponents referred to advantages in the form of increasing the legitimacy of the practice of presidential oversight through use of $c b a$, insuring that oversight based on cba continues to be used in the future, and enlisting the assistance of courts in the process of using cba to insure that the benefits of each rule exceed the costs imposed by the rule. 
Some of the disadvantages of the codification proposals differ depending on whether the proposal is to codify through use of the rulemaking process or through use of the legislative process. In the rulemaking context, there are serious questions whether OIRA has the power to issue such a rule. In the legislative context, there are serious questions whether Congress would enact such a statute.

Codification through either means could produce problems of excessive rigidity. It is extremely difficult to amend a rule or a statute. That greatly increases the importance of wording the statute in ways that minimize the risk that it will be misinterpreted and in ways that provide future presidents and OIRA the flexibility required to permit changes in the methods of implementing presidential oversight and application of cba as the need for changes arise.

Giving courts responsibility to review agency and OIRA applications of cba also would create the risk that reviewing courts might act in ways that frustrate the efforts of agencies and OIRA to apply cba correctly. Judges are well-educated in law but most judges are not well-educated in economics or other disciplines that depend on familiarity with quantitative tools. As a result, courts often make major mistakes in the process of applying basic principles of science and social science when they review agency actions.

The majority opinion of the Supreme Court in Industrial Union Department, AFL-CIO v. American Petroleum Institute ${ }^{5}$ provides a good example of that common occurrence. After holding that the Occupational Safety and Health Administration was required to find that there was a pre-existing "significant risk" to workers' health as a result of exposure to some toxic substance before the agency could regulate the substance, the majority decided to help the agency understand the holding by giving contrasting examples of an insignificant risk that is "plainly acceptable" and a significant risk that is "plainly unacceptable." There was a problem with the examples the Court used to illustrate that difference, however. Application of the first principle of toxicology and fourth grade math shows that the risk the

\footnotetext{
${ }^{5} 448$ U.S. 607, 655 (1980).
} 
Court called "insignificant" would kill about 93,440 people while the risk the Court called "significant" would kill far fewer people.

Giving Congress an increased role in regulatory oversight. Several participants urged adoption of ways of giving Congress a greater role in reviewing the process of issuing rules, including creating an agency in Congress that would review agency cbas in much the same manner as OIRA. In theory, changes of that type would be helpful in two ways. First, Congress could serve as a check on the honesty and competence of the executive branch and the president. Second, giving Congress an increased role in regulatory oversight would enhance the political legitimacy of agency regulation and the process of presidential oversight of the regulatory process.

Unfortunately, the reality of the modern legislative process provides little reason to believe that we would actually enjoy the advantages that increasing the congressional role in the review process offer in theory. For reasons that I have discussed in detail elsewhere, ${ }^{6}$ Congress has become almost completely impotent. It is unlikely that Congress can regain its ability to act effectively without major changes in the ways that we choose candidates for office and the leaders of the House and Senate. On the rare occasions on which Congress acts, its pattern of actions suggests that it has little interest in furthering the goal of ensuring that rules confer net benefits on society.

The history of uses of the Congressional Review Act (CRA) illustrates both the impotence of Congress most of the time and its lack of interest in maximizing social welfare on those rare occasions when it acts. Congress enacted the CRA in 1996 in an attempt to create an easy means through which Congress can veto any agency rule that it dislikes. The CRA incorporates a variety of tools that are designed to make it easy for Congress to veto a rule that Congress dislikes. The House and Senate are required to give priority

\footnotetext{
${ }^{6}$ Richard J. Pierce, Jr., Delegation, Time, and Congressional Capacity, forthcoming in lowa Law Review in 2019, available on Social Science Research Network.
} 
to any resolution to veto a rule; amendments are prohibited; floor debate is limited; and the usual requirement of sixty votes for cloture in the Senate does not apply.

Yet with all of those mechanisms in place to expedite the process of vetoing a rule, the CRA was used only once between 1996 and 2017. There are only two potential explanations for the lack of use of the CRA for over twenty years. Either no agency issued a rule that Congress disliked for over twenty years, or even with access to mandatory expedited procedures it was virtually impossible for Congress to take any legislative action to veto a rule it disliked. Only the second potential explanation seems plausible. That illustrates the impotence of Congress in most circumstances.

In 2017, Congress used the CRA to veto fifteen agency rules. Those actions were not the product of careful evaluation of the hundreds of rules that were eligible for veto in 2017, however. When Dan Farber compared the handful of rules that were vetoed with the many rules that were eligible for veto but were not vetoed, he was unable to identify any principle that could explain why a few rules were vetoed and most were not. ${ }^{7}$ The vetoed rules were not particularly important, and their ratio of costs to benefits did not differ from those of the rules that were not vetoed. This suggests that the decisions were based solely on complaints from a few politically powerful interest groups that disliked a handful of rules.

Reconciling CBA with political accountability. Stuart Shapiro notes that OIRA must attempt to further simultaneously two goals-maximize the net social benefits that rules produce as measured by cba and ensure that the rules that agencies issue are consistent with the preferences of the public as those preferences are understood by the president. He recognizes that those goals often conflict, and that OIRA has never been able to further both on a consistent basis in any administration.

\footnotetext{
${ }^{7}$ Farber, supra. note 2.
} 
Shapiro expresses concern that the gap between actions that are based on political accountability to the president and actions that maximize social welfare is particularly large in the Trump Administration. He then evaluates several possible ways of addressing that gap. After acknowledging that none of the alternatives "are without flaws" he urges an increase in the role of Congress in the process of overseeing the actions of agencies through application of cba.

I agree with Shapiro that OIRA's twin goals often conflict and that the conflict is greater in the Trump Administration than it has been in any prior administration. I also agree with him that none of the potential solutions to the problem that he identifies is free of flaws. I prefer his "Do Nothing" alternative, however.

I don't like Shapiro's proposal to give Congress a greater role for the reasons I stated in the last section of this essay. There are two other problems with that option. First, the gap between the goal of maximizing the net benefits of regulation as measured by cba and the goal of ensuring that agencies act in accordance with the preferences of the public, as those preferences are perceived by Congress, is likely to be as large as the gap between the goal of maximizing the net social benefits of regulation as measured by cba and ensuring that agencies act in accordance with the preferences of the public, as those preferences are perceived by the President. Second, there is no reason to believe that Congress has a better understanding of the preferences of the public than the president.

It may be regrettable that the public often has preferences that are based on emotion and ignorance rather than careful evaluation of facts, and that politicians usually act on the basis of the preferences of the public, but that is the price we pay for living in a Democracy. As then Lieutenant Tozzi explained in an article he wrote fifty years ago, cba cannot alone form the basis for government decisions because cba tends to disguise the value judgments that necessarily form the basis for government decisions in a Democracy. ${ }^{8}$ The president's preferences are as good a proxy for the preferences of the public as we can

\footnotetext{
8 Jim Tozzi, Establishing Priorities for Public Investment. Defense Technical Information Center (June 1969).
} 
find. We will know whether President Trump has accurately perceived the preferences of the public when we see the results of the 2020 election. 